\title{
A Cell-based Drug Efflux Assay for Analysis of Multidrug Resistance in Cancer Patients
}

\author{
Arvinder Singh ${ }^{1, *}$ and Saranpal Singh ${ }^{2}$ \\ ${ }^{1}$ Department of Biopharma Sciences, Chandigarh Group of Colleges, Gharuan, Mohali (Punjab), India. \\ ${ }^{2}$ Department of Biochemistry, Gian Sagar Medical College and Hospital, Banur, Patiala (Punjab), India. \\ *Corresponding author \\ Dr. Arvinder Singh \\ Assistant Professor (HOD), \\ Department of Biopharma Sciences, Chandigarh Group of Colleges, \\ Gharuan, Mohali (Punjab), India. \\ Tel: +919878281115 \\ Email: arvin111@gmail.com
}

Received: 8 November 2009; | Revised: 21 December 2009; | Accepted: 2 January 2010

\begin{abstract}
Multidrug Resistance (MDR) is a phenomenon where many tumor cells selected for resistance to a single agent are cross-resistant to several structurally and functionally unrelated compounds. Polymorphisms of genes encoding for xenobiotics and drug transporters are potential factors, which can influence the risk of developing cancer and its clinical outcome. The single-nucleotide polymorphism C3435T of MDR1 gene has been found to be associated with altered tissue expression and function of Permeability-glycoprotein (PGP). In the present study efflux of drug amongst different genotypes was studied using cell based assay. Drug uptake of the cells was found to be maximum in the cells that showed homozygous TT genotype in contrast to the cells with homozygous CC genotype that showed minimum drug uptake. This method is a novel approach for the study of such kind of pharmacokinetics. The results of the present study may prove very helpful in the treatment of cancer patients.
\end{abstract}

Keywords: ATP-binding Cassette; Multidrug resistance; Permeability-glycoprotein;

Single nucleotide polymorphism.

\section{Introduction}

ATP-binding cassette $(\mathrm{ABC})$ transporters are members of a DNA superfamily which are transmembrane proteins that function in the transport of a wide variety of substrates across extra and intracellular membranes, including Am. J. Biomed. Sci. 2010, 2(2), 178-183; doi: 10.5099/aj100200178 metabolic products, lipids and sterols, and drugs in organisms ranging from bacteria to humans. [1] Members of this family modulate a broad spectrum of physiological functions such as absorption (MDRs), metabolism (ABCA1), detoxification (ABCB1) etc. [2]. ABC transporters are known to play a crucial role in the () 2010 by NWPII. All rights reserved. 
development of multidrug resistance (MDR), a condition enabling a disease-causing organism to resist distinct drugs or chemicals of a wide variety of structure and function targeted at eradicating the organism.

Prevention of this cancer multi-drug resistance will improve cancer patients' response to implemented therapeutic approaches. Cancer multi-drug resistance can be overcome by developing therapeutic agents that will not interact with the membrane proteins or by pharmacologically modifying the $\mathrm{ABC}$ proteins with MDR modifying agents. MDR modifying agents such as R-verapamil and PSC-833 diminish the membrane proteins recognition of the cytotoxic drugs thus preventing its efflux into the extracellular environment. [3].

P-glycoprotein gives rise to resistance to drugs used for chemotherapy. Tamoxifen is one of the substrate for P-gp and is used in the treatment of breast cancer. It is an orally taken selective estrogen receptor modulator (SERM) and is currently the world's largest selling drug for that purpose. Tamoxifen competitively binds to estrogen receptors on tumors and other tissue targets, producing a nuclear complex that decreases DNA synthesis and inhibits estrogen effects. It is a non-steroidal agent with potent antiestrogenic properties which compete with estrogen for binding sites in cancerous tissues [4]. Tamoxifen causes cells to remain in the G0 and G1 phases of the cell cycle. Because it prevents (pre)cancerous cells from dividing but does not cause cell death, tamoxifen is cytostatic rather than cytocidal.

Tamoxifen itself is a prodrug, having relatively little affinity for its target protein, the estrogen receptor. It is metabolized in the liver by the cytochrome P450 isoform CYP2D6 and CYP3A4 into active metabolites such as 4hydroxytamoxifen and N-desmethyl-4hydroxytamoxifen (endoxifen) which have 30-100 times more affinity with the estrogen receptor than tamoxifen itself. These active metabolites compete with estrogen in the body for binding to the estrogen receptor.

The present investigation highlights the development of a novel cell based drug efflux assay. This assay has been used for the analysis of the behavior of the ABCB1 gene product, $\mathrm{P}$ glycoprotein $(\mathrm{P}-\mathrm{gp})$ transporter that is involved in the phenomenon of drug resistance. Briefly, known amounts of drug (Tamoxifen) was added to cultured cells. The concentrations of intracellular and extracellular drug present in these different cultures representing different genotypes were measured by High Performance Liquid Chromatography (HPLC). This method is precise, accurate and allows for the direct measurement of the drug. Till date very less information is available regarding the standard HPLC assay. Such an assay can be used for the study of pharmacogenetics of different MDR1 drug substrates

\section{Materials and methods}

Human blood samples were collected from females ( $n=50$, aged 18-50 years), who were seeking treatment for breast cancer at Mohan Dai Oswal Cancer Hospital, Ludhiana, India. Ethical clearance was obtained from the Ethics Committee of the Hospital. All study participants or their parents or guardians gave informed written consent. Relevant information such as treatment, clinical and follow-up surveillance was also been recorded. The genotypic analysis of the genomic DNA was carried out using PCR-RFLP [5]. Following the results of genotyping the patients were categorized into three different types i.e. CC, CT and TT for further analysis of drug uptake amongst them.

\subsection{Cell culture}

Sample tubes were autoclaved and heparinized with $0.05 \mathrm{ml}$ of heparin. $2 \mathrm{ml}$ of blood was collected in a sterile disposable tube containing $0.1 \mathrm{ml}$ heparin. Prepared $10 \mathrm{ml}$ cultures by adding $8 \mathrm{ml}$ of RPMI 1640 supplemented with $0.15 \mathrm{ml}$ of PHA and $2 \mathrm{ml}$ of supernatant plasma from sample tube. $0.4 \mathrm{ml}$ of leucocytes from the buffy coat along with a few red cells were aspirated and added to culture bottles and mixed thoroughly. The mouth of the culture bottles were sealed and incubated in a preset $37{ }^{\circ} \mathrm{C}$ incubator for $70 \mathrm{hrs}$. The bottles were shaken thrice daily. Tamoxifen was added to a final concentration of $100.0 \mu \mathrm{g} / \mathrm{ml}$. The cultures were incubated at $37^{\circ} \mathrm{C}$ 
for an additional 2 hrs. The cultures were centrifuged at $8000 \mathrm{rpm}$ for $10 \mathrm{~min}$. The supernatant was preserved in a separate vial leaving about $0.5 \mathrm{ml}$ of the supernatant in the tube. The pellet of cells was re-suspended in the remaining $0.5 \mathrm{ml}$ supernatant [6].

\subsection{Viable cell count}

A Hemocytometer was used to count the cells before the addition of the drug at $70 \mathrm{hrs}$. The volume of RPMI used was adjusted to ensure that the cell concentrations were consistent in all the samples $\left(5 \times 10^{5}\right.$ cell $\left./ \mathrm{ml}\right)$. The Percentage cell viability of cells was carried out by using Trypan blue dye exclusion technique. The percentage cell viability of the cells was found to be $81.13 \%$.

\subsection{Extraction of extracellular drug from supernatant}

The supernatant was warmed followed by the addition of $2 \mathrm{ml}$ of $5 \mathrm{M}$ sodium hydroxide and then cooled. Extracted with two 10-ml quantities of ether, filtering each extract in turn. The ether extracts were combined and evaporated to dryness at room temperature. The remaining extract was re-dissolved into $1 \mathrm{ml}$ of methanol.

\subsection{Extraction of intracellular drug from cell pellet}

The pellet of cells was reconstituted in $1 \mathrm{ml}$ RPMI 1640. The cells were sonicated for a total of $3 \mathrm{~min}$, giving pulses of $30 \mathrm{sec}$. The cells were centrifuged at $5000 \mathrm{rpm}$ for $5 \mathrm{~min}$. The supernatant was collected and the drug was extracted as before.

\subsection{HPLC Assay for Tamoxifen}

$10 \mu \mathrm{l}$ of the dissolved drug was injected onto the Beckman ODS reverse phase $\mathrm{C}_{18}$ HPLC column (4.6 X150 mm, 5- $\mu \mathrm{m}$ particle size). The compound was analyzed using a Shimadzu LC10ATvp HPLC system, with a mobile phase of methanol (A): ammonium acetate (B) $(50 \mathrm{mM}(\mathrm{pH}$ $7.0)$ ) in the ratio of $95 \% \mathrm{~A}: 5 \% \mathrm{~B}$, at a solvent flow rate of $1 \mathrm{ml} / \mathrm{min}$. The drug was detected using a UV-VIS detector at $270 \mathrm{~nm}$. The peak area of Tamoxifen was used to calculate the concentration of Tamoxifen in various samples, using extracted standard curve of pure compound.

\section{Results and discussion}

Orthodox cancer treatments such as chemotherapy, radiotherapy, and surgery have proved to be ineffective cancer treatments as a result of its toxicity [7]. Membrane proteins also known as multi-drug transporters are responsible for the development of drug resistance as they expel the cytotoxic molecules from the cell, resulting in intracellular drug concentrations that are below the cell-killing threshold.

In the present investigation, accurate methodology was designed for the estimation of drug concentration inside the cells. The HPLC assay standardized for the estimation of drug is very accurate and reliable. The need to develop such an assay was due to the nonavailability of any other method. There are several human in vitro methods that have been developed to study hepatic metabolism and possible interactions between drugs [8]. Methods such as gas chromatographic mass spectrometry (GC-MS) [9] and high performance thin layer chromatography (HPTLC) [10] have been described for measuring plasma or tissue levels of xenobiotics. The drawbacks of these methods are that while using GC-MS the drug must be dissolved and derivatized before analysis, making the process both destructive and time consuming. The major drawback of HPTLC is that it has low sensitivity, low specificity and it is not quantitative. In the present methodology there is no such issue.

Another method for the estimation of drugs is through the use of radioactive substrates [11]. But again the drawback is that most test compounds are not available in a radioactive labeled form. Another approach is to label the substrate with fluorescent dyes. As most test drugs are nonfluorescent, this assay is also usually performed in an "indirect" set-up, using a fluorescent reporter substrate, such as Rhodamine 123 (R123) [12]. The drawbacks of using fluorescent dyes are (i) the dye displays poor cellular retention, and it interacts with different intracellular compartments resulting in a spectral and intensity shift [13], (ii) the initial concentration is cell-type dependent and (iii) the concentration of the dye changes during the measurement. It has also been reported that

C 2010 by NWPII. All rights reserved. 
after the initial loading, cells have to be incubated for 1-2 [14], or even 3-10 hours in clinical samples [15]. This long timeframe and the extensive washing of the cells prior to the plate reader analysis, makes this assay inapplicable for high throughput screening (HTS).
The HPLC assay is very fast and accurate. As shown in fig 1, single peak has been observed for the purified drug at a retention time of 5.44 min. Similarly the patient samples with different genotypes i.e. CC, CT and TT has also been analysed and calculated for drug concentration.

\section{Chrom atogram}

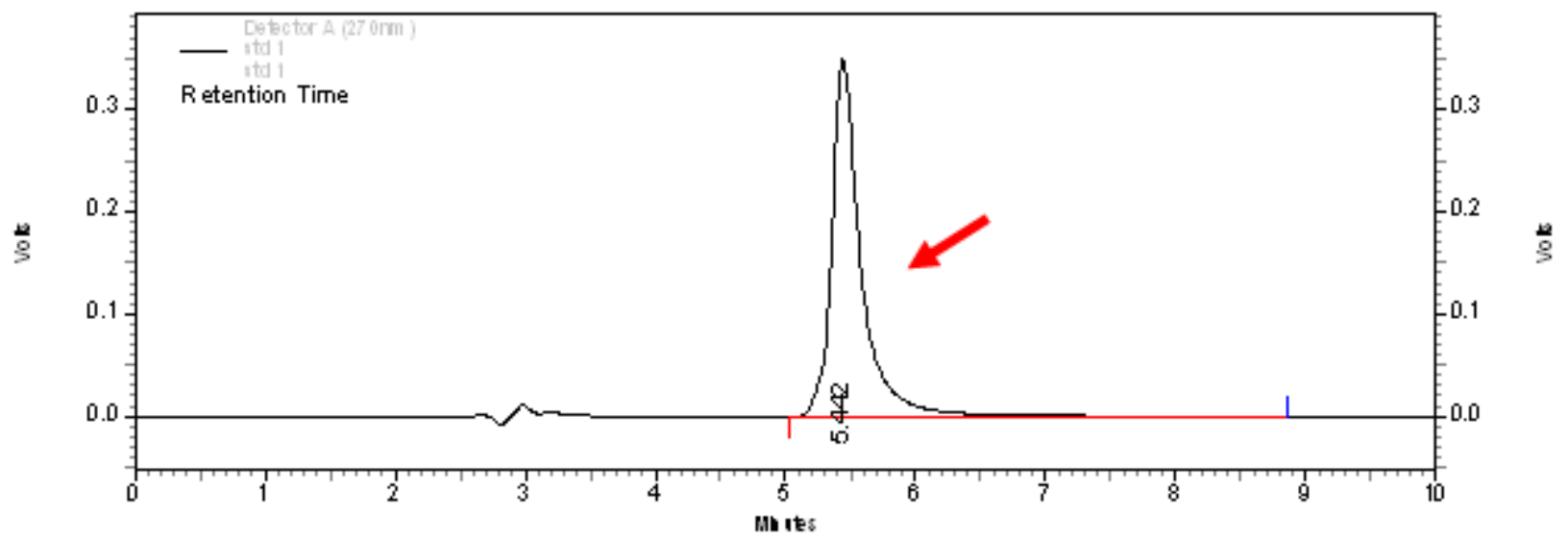

(10.0 ug/ul; Injection Volume - 10 micro liter)

Figure 1. Chromatogram showing single peak for purified Tamoxifen

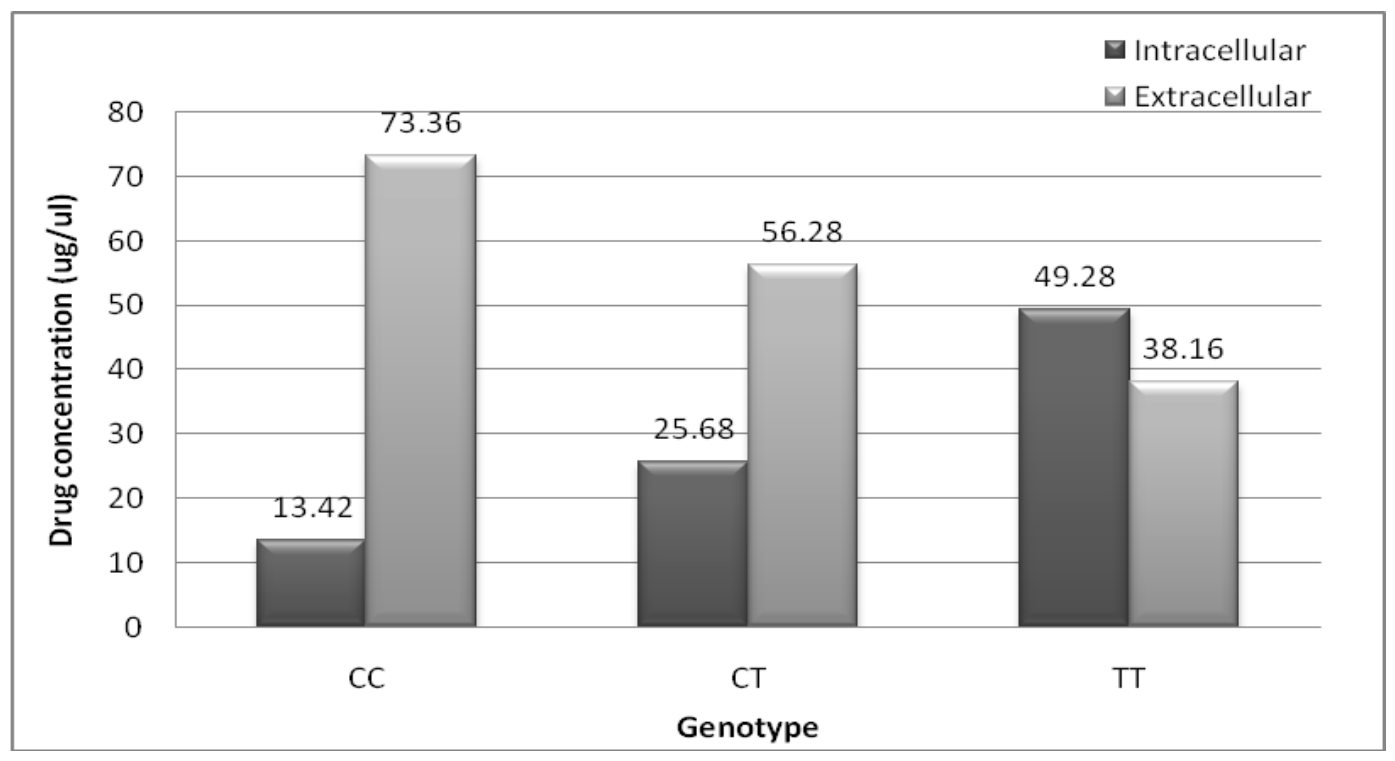

Figure 2. Concentration of drug in various genotyped samples

It has been observed that the average drug uptake of the samples with CC genotype was found to be $13.42 \mathrm{ug} / \mathrm{ul}$ which was much below than that of CT and TT i.e. 25.6 and $49.2 \mathrm{ug} / \mathrm{ul}$ respectively (Fig 2). The results were in agreement with the in vivo drug response of the patients 
undergoing chemotherapy. Patients with CC genotype were more resistant to chemotherapy than those bearing TT. The resistance so developed in the cells with $\mathrm{CC}$ is due to more of the presence of P-gp in them.

\section{Conclusion}

The cell based assay can help to know the required chemotherapy to be given to the patents accurately and in much short time which significantly benefit cancer patients.

\section{Acknowledgement}

The authors are grateful to Mohan Dai Oswal Cancer Hospital, Ludhiana, for providing blood samples of cancer patients.

\section{References}

1. Juliano, R.L.; Ling, V. A surface glycoprotein modulating drug permeability in Chinese hamster ovary cell mutants, Biochim. Biophys. Acta, 1976, 455(1), 152- 162.

2. Kruijtzer, C.M.; Beijnen, J. H.; Schellens, J.H. Improvement of Oral Drug Treatment by Temporary Inhibit ion of Drug Transporters and/or Cytochrome P450 in the Gastrointestinal Tract and Liver: An Overview, The Oncologist, 2002, 7 (6), 51630.

3. Litman, T.; Druley, T.E.; Stein, W.D.; Bates, S.E. From MDR to MXR: new understanding of multidrug resistance systems, their properties and clinical significance, Cell. Mol. Life Sci., 2001, 58 (7), 931- 59.

4. Tucker, A.N.; Tkaczuk, K.A.; Lewis, L.M.; Tomic, D.; Lim, C.K.; Flaws, J.A. Polymorphisms in cytochrome P4503A5 (CYP3A5) may be associated with race and tumor characteristics, but not metabolism and side effects of tamoxifen in breast cancer patients, Cancer Letters, 2005, 217, 61- 72.

5. Jamroziak, K.; Balcerczak, E.; Mtynarski, W.; Mirowski, M; Robak, T. Distribution of Allelic Variants of Functional C3435T Polymorphism of Drug Transporter MDR1
Gene in a Sample of Polish Population. Polish Journal of Pharmacology, 2002, 54: 495-500.

6. Moorhead, P.S.; Nowell, P.C.; Mellman, W.J.; Battips, D.M.; Hungerford, D.A. Chromosome preparations of leucocytes cultured from human peripheral blood, Exp. Cell Res., 1960, 20, 613

7. Curtis, R. E.; Boice, J. D.; Stovall, M.; Bernstein, L.; Greenberg, R. S.; Flannery, J. T.; Schwartz, A. G.; Weyer, P.; Moloney, W. C.; Hoover, R. N. Risk of leukemia after chemotherapy and radiation treatment for breast cancer, The New England journal of medicine, 1992, 326(26), 1745-51.

8. Venkataramanan, R.; Kuehl, P.; Zhang, J.; Lin, Y.; Lamba, J.; Assem, M.; Schuetz, J.; Watkins, P.B.; Daly, A.; Wrighton, S. A.; Hall, S. D.; Maurel, P.; Relling, M.; Brimer, C.; Yasuda, K.; Strom, S.; Thummel, K.; Boguski, M. S.; Schuetz, E. Sequence diversity in CYP3A promoters and characterization of the genetic basis of polymorphic CYP3A5 expression, Nature Genetics, 2001, 27: 383- 391.

9. Gaskell, S. J.; Daniel, C. P.; Nicholson, R. I. Determination of tamoxifen in rat plasma by gas chromatography-mass spectrometry, Journal of Endocrinology, 1978, 78, 293-294.

10. Adam, H. K.; Gay, M. A.; Moore, R. H. Measurement of tamoxifen in serum by ThinLayer Densitometry, Journal of Endocrinology, 1980, 84, 35-42.

11. Reid, G.; Wielinga, P.; Zelcer, N.; De Haas, M.; Van Deemter, L.; Wijnholds, J.; Balzarini, J.; Borst, P. Characterization of the Transport of Nucleoside Analog Drugs by the Human Multidrug Resistance Proteins MRP4 and MRP5, Mol. Pharmacol., 2003, 63 (5), 1094103.

12. Feller, N.; Kuiper, C.M.; Lankelma, J.; Ruhdal, J.K.; Scheper, R.J.; Pinedo, H.M.; Broxterman, H.J. Functional detection of MDR1/P170 and MRP/P190- mediated multidrug resistance in tumour cells by flow cytometry, Br. J. Cancer, 1995, 72 (3), 543- 9.

13. Weaver, J.L.; Pine, P.S.; Aszalos, A.; Schoenlein, P.V.; Currier, S.J.; Padmanabhan, R.; Gottesman, M.M. Laser scanning and 
confocal microscopy of daunorubicin, doxorubicin, and rhodamine 123 in multidrugresistant cells, Exp. Cell. Res., 1991, 196 (2), 323- 329.

14. Lee, J.S.; Paull, K.; Alvarez, M.; Hose, C.; Monks, A.; Grever, M.; Fojo, A.T.; Bates, S.E. Rhodamine efflux patterns predict Pglycoprotein substrates in the National Cancer
Institute drug screen. Mol. Pharmacol., 1994, 46 (4), 627- 638.

15. Chaudhary, P.M.; Robinson, I.B. Expression and activity of $\mathrm{P}$ - glycoprotein, a multidrug efflux pump, in human hematopoietic stem cells, Cell, 1991, 66, 85- 94. 